\title{
Multiple halogen components in subcontinental lithospheric mantle
}

H. SUMINO ${ }^{1}$, S. NIKI ${ }^{2}$, M. KOBAYASHI ${ }^{3}$, H. KAGI ${ }^{2}$ AND

\author{
R. BURGESS ${ }^{4}$
}

${ }^{1}$ Dept. Basic Sci., Univ. Tokyo, Tokyo 153-0041, Japan

(*correspondence: sumino@igcl.c.u-tokyo.ac.jp)

${ }^{2}$ Geochem. Res. Cen., Univ. Tokyo, Tokyo 113-0033, Japan

${ }^{3}$ Tokyo Metro. Ind. Tech. Res. Inst., Tokyo 135-0064, Japan

${ }^{4}$ Sch. Earth Environ. Sci., Univ. Manchester, Manchester

M13 9PL, UK

Volatile recycling back to the Earth's mantle at subduction zones has a significant, yet poorly constrained impact to the volatile budget in the mantle. Halogens with marine pore-fluid signatures have previously been discovered in mantle wedge peridotites, suggesting that pore-fluidderived volatiles can survive the subduction cycle to subarc depths and modify the subcontinental lithospheric mantle (SCLM) $[1,2]$. To better constrain how such subduction fluids modifies the halogen composition of SCLM, we analyzed halogens in single grains/ a few grains of olivine, ortho- and clino-pyroxene crystals separated from mantle xenoliths from Southern Patagonia, Kamchatka, and the Philippines, in which several halogen components in addition to a MORBlike one have been previously identified in bulk and mineral separates [2,3]: (A) a pore-fluid-like component with high $\mathrm{Br} / \mathrm{Cl}$ and $\mathrm{I} / \mathrm{Cl}$ ratios similar to bulk mantle wedge peridotites [1,2]; (B) a Cl-enriched component relative to MORB, similar to bulk altered oceanic crust (AOC) and metasomatised intraplate mantle xenoliths [4,5]; and (C) a component enriched in $\mathrm{Br}$ and moderately in I compared to MORB, which resembles fluids in AOC, diamonds and mantle xenoliths in Russian kimberlites [4,6,7]. Halogens in the mineral grains were measured with neutron-irradiation and noble gas mass spectrometry combined with crushing and laser heating extraction.

Whereas only component (A) was observed in bulk samples from Kamchatka and the Philippines containing abundant water-rich fluid inclusions [2], components (B) and (C) were also identified in their olivines. In contrast, the component (A) is a relatively minor component in Southern Patagonian samples. These suggest that mantle wedge metasomatism by pore-fluid derived volatiles would be obscured by fractionation processes in SCLM [5], while AOC-related signatures survive more robustly.

[1] Sumino et al. (2010) EPSL. [2] Kobayashi et al.(2017) EPSL. [3] Sumino et al. (2018) Goldschmidt abstract. [4] Chavrit et al., (2016) GCA. [5] Kobayashi et al. (2019) Gcubed. [6] Burgess et al. (2009) GCA. [7] Broadley et al. (2018) Nature Geo. 